\title{
Associations between circulating inflammatory markers, diabetes type and complications in youth
}

Running title: Inflammation and diabetes in youth

Authors: Juliane Aulich ${ }^{1,2}$, Yoon Hi Cho ${ }^{2}$, Andrzej S Januszewski ${ }^{3}$, Maria E Craig ${ }^{2,4,5}$, Hiran Selvadurai $^{2,4}$, Susanna Wiegand ${ }^{1}$, Alicia J Jenkins ${ }^{3,4}$, Kim C Donaghue ${ }^{2,4}$

Institutions: ${ }^{1}$ Charité Universitätsmedizin Berlin, ${ }^{2}$ The Children’s Hospital at Westmead, Sydney, ${ }^{3}$ NHMRC Clinical Trials Centre, Sydney, ${ }^{4}$ The University of Sydney, ${ }^{5}$ University of New South Wales

Words: Abstract 261

Main Body 4188

Tables 3 Figures 2

\section{Corresponding author:}

Prof. Kim Donaghue

Institute of Endocrinology and Diabetes

The Children’s Hospital at Westmead, Sydney

NSW 2145, Australia

Phone: +61 298451400

email: kim.donaghue@health.nsw.gov.au

This is the author manuscript accepted for publication and has undergone full peer review but has not been through the copyediting, typesetting, pagination and proofreading process, which may lead to differences between this version and the Version of Record. Please cite this article as doi: $10.1111 /$ pedi.12913

This article is protected by copyright. All rights reserved. 
Key Words: diabetes, Type 1 diabetes, Type 2 diabetes, cystic fibrosis-related diabetes, inflammation, youth, clinical research 


\section{Abstract:}

Background: Inflammation is implicated in the pathogenesis of diabetes and its complications in adults. Little is known about the relative contribution of inflammation in common types of diabetes in youth: Type 1 diabetes (T1D), Type 2 diabetes (T2D) and cystic fibrosis-related diabetes (CFRD). This study investigates inflammatory markers by diabetes type and complication status, and assesses indicators of inflammation and complications.

Methods: A cross-sectional study of 134 T1D, 32 T2D, 32 CFRD and 48 subjects without diabetes (including 11 with CF and normal glucose tolerance) was undertaken. Inflammation was assessed by sE-selectin by ELISA, hsCRP by turbidometry, WCC and ESR. Nephropathy was defined by albuminuria, autonomic neuropathy by heart rate variability, and peripheral neuropathy by vibration and thermal threshold testing and retinopathy by seven-field stereoscopic fundus photography. Descriptive statistics, parametric and non-parametric ANOVA and regression analyses were performed, with significance at $\mathrm{p}<0.05$.

Results: Of 198 diabetic participants; 49\% female, mean (SD) age, median diabetes duration and median HbA1c were 16(2.5) and 6(3-9) years and 8.1(6.9-9.3)\%, respectively. All inflammatory markers were lower in T1D than in other diabetes groups $(\mathrm{p}<0.05)$ but higher than in non-diabetic controls. T2D $(n=32)$ and CFRD $(n=32)$ subjects had comparable elevated levels of inflammation. BMI was a strong independent explanatory variable of inflammation. In multivariate analysis, hsCRP and ESR were associated with complications in addition to HbA1c, BMI and diastolic BP.

Conclusions: Circulating inflammatory markers are elevated in adolescents with diabetes, being higher and comparable in T2D and CFRD than in T1D. Inflammation is independently 
associated with diabetes complications, consistent with inflammation driving vascular pathology in diabetes.

This article is protected by copyright. All rights reserved. 


\section{Introduction}

Inflammation has been implicated in the pathogenesis of both diabetes mellitus ${ }^{1}$ and its chronic complications in adults ${ }^{2,3}$, in particular with Type 2 diabetes (T2D) ${ }^{4,5}$. Similarly, obesity is a risk factor for $\mathrm{T} 2 \mathrm{D}$ and is also associated with complications, including nephropathy ${ }^{6}$ and retinopathy ${ }^{7}$, in adults with Type 1 diabetes (T1D). The adiposity effect may be mediated by associated dyslipidemia, hypertension, and increased inflammation. Examining these risk factors in youth may clarify the interactions and will extend knowledge. In youth there are several common types of diabetes: T1D, T2D, and cystic fibrosis-related diabetes (CFRD). The latter is usually associated with systemic and pulmonary inflammation due to infection, without obesity ${ }^{8,9}$.

Circulating inflammatory markers include white cell count (WCC), the erythrocyte sedimentation rate (ESR), and C-reactive protein (CRP), which is produced in many tissues, including adipocytes, the liver, and the vasculature ${ }^{10}$. WCC, ESR and CRP assays are commonly available in clinical pathology laboratories, whilst other inflammatory markers (e.g. vascular cell adhesion molecules (CAMs) are research tools requiring informed consent, ethics approvals, additional blood sample, and specialized assays. CRP levels are often correlated with body mass index (BMI); in particular, with adiposity ${ }^{11}$ and with infections ${ }^{10}$, with CRP levels above $10 \mathrm{mg} / \mathrm{L}$ being likely due to concurrent infection ${ }^{12}$. CAMs, including sE-selectin, sVCAM-1 and sICAM, are expressed by arterial endothelial cells and are research markers of vascular inflammation. CAM levels often correlate with each other as they are part of a chain reaction of monocyte adhesion, rolling, and arterial wall ingress, in which they become macrophages, accumulate lipoproteins, including native and modified 
(e.g., glycated and oxidized) low-density lipoprotein (LDL) and cause atherosclerosis ${ }^{13}$. Soluble forms of the CAMs are shed into the circulation, the levels of which have been associated with, and are predictive of, cardiovascular disease in adults in the general and diabetic population, as well as of the microvascular complications of $\mathrm{T}^{1} \mathrm{D}^{14,15}$.

As little is known about inflammation levels and the three common forms of diabetes in youth we conducted an observational cross-sectional study of children and adolescents with T1D, T2D, and CFRD to assess levels of inflammation and their relationships to diabetes type and chronic complications. We hypothesized that the level of inflammatory markers (a) is higher in all forms of diabetes compared to non-diabetic reference groups; (b) is associated with the complication status of diabetic patients independently of glycemic control and diabetes duration; and that (c) obesity in diabetic youth, reflected by higher BMI, is associated with increased levels of inflammatory markers.

\section{Methods}

This cross-sectional study was approved by the Human Research Ethics Committees at The Children's Hospital at Westmead (CHW) and the University of Sydney, and all participants and their families provided written informed consent. hsCRP and sE-selectin were measured in those with diabetes and in those without diabetes: Those with diabetes underwent complications assessments with measurement of WCC and ESR and other laboratory tests. WCC and ESR measures were not performed in the non-diabetic reference groups and comparisons could only be made with standard reference values from CHW.

This article is protected by copyright. All rights reserved. 


\section{Subjects}

The study group was 198 youth with diabetes attending the CHW Sydney during 2011-17: (i) 134 adolescents with T1D diagnosed clinically and confirmed by low C-peptide levels and positive autoantibody status; (ii) 32 adolescents with T2D diagnosed clinically with negative autoantibodies and without maturity onset diabetes of the young (MODY) or secondary diabetes mellitus; and (iii) 32 adolescents with CFRD defined as a fasting blood glucose (BGL) $>7 \mathrm{mmol} / \mathrm{L}$ or 2-hour BGL $>11.1 \mathrm{mmol} / \mathrm{L}$, in the most recent oral glucose tolerance test (OGTT) or hemoglobin A1c (HbA1c) >6.5\%) in association with cystic fibrosis (CF). Participants were recruited during their diabetes complications assessment service (DCAS) visit: after 2 years T1D when diagnosed $\geq 11$ years or after 5 years duration when diagnosed $<11$ years old; T2D and CFRD at diagnosis. Eligibility criteria were stable disease, absence of severe hypoglycaemia in the prior six months, without evident acute infection, and lack of oral corticosteroid treatment for at least 4 weeks. None of the included CF patients was treated with CF-channel drugs.

Two age- and gender-matched reference groups of 37 apparently healthy youth from families of hospital patients or staff members and 11 CF patients with normal glucose tolerance were recruited during 2011-17. First degree relatives of diabetes patients were eligible if they had negative diabetes antibodies, and were free from chronic inflammatory medical conditions, intercurrent fever or infection. CF patients without diabetes were eligible if they had no evident infection and were not taking oral corticosteroids for at least 4 weeks. 


\section{Diabetes clinical and complications assessment}

Height (Harpenden stadiometer) and weight (electronic scales) were measured and BMI calculated (weight $(\mathrm{kg}) /$ height $(\mathrm{m})^{2}$ ) and height, weight and BMI standard deviation scores (SDS) calculated according to the least means square (LMS) method ${ }^{16}$. Weight categories (underweight: $<15^{\text {th }}$ percentile; normal: $\geq 15^{\text {th }}$ percentile and $\leq 85^{\text {th }}$ percentile; overweight: $>85^{\text {th }}$ percentile and $<97^{\text {th }}$ percentile; and obese: $\geq 97^{\text {th }}$ percentile) were as per World Health Organization (WHO) standards ${ }^{17}$. Blood pressure (BP) was measured by auscultation after 5 minutes (min.) rest in a seated position, with age and sex-related SDS for systolic BP (SBP) and diastolic BP (DBP) calculated according to established standards ${ }^{18}$. Hypertension was defined as BP levels $\geq 95^{\text {th }}$ percentile for age ( $<18$ years), $\geq 140 / 90 \mathrm{~mm} \mathrm{Hg}$ ( $\geq 18$ years), or relevant medical therapy.

A non-fasting 10ml blood sample was collected by venipuncture and a timed overnight urine sample collected. Approximately $8 \mathrm{ml}$ blood and at least $5 \mathrm{ml}$ of urine were sent to the central laboratory of CHW for immediate analyses for non-fasting lipids, WCC and ESR and urinary albumin creatinine ratio (ACR).

Diabetic nephropathy was defined as microalbuminuria (either AER $\geq 20 \mu \mathrm{g} / \mathrm{min}$ in at least two of three samples from timed overnight collections or mean ACR $\geq 3.5$ (male) / $\geq 4$ (female) $\mathrm{mg} / \mathrm{mmol}$ from three first morning collections). 
Heart rate variability (HRV), a measure of cardiac autonomic function, was assessed as previously described $^{19}$, using LabChart Pro (AD Instruments, Sydney, NSW, Australia), based on a 10 min continuous EKG (ectopics excluded) in rested supine patients. One operator visually scanned the trace for R-waves among artifacts and ectopic beats. Time-domain HRV measures included three different categories: baseline heart rate, the standard deviation of the R-R interval (SDNN), and root mean squared difference of successive R-R intervals (RMSSD). Frequency domain measures included four further categories: low frequency (LF), defined as $>0.04 \mathrm{~Hz}$ and $<0.15 \mathrm{~Hz}$, considered as sympathetic component, and high frequency (HF) components, defined as $>0.15 \mathrm{~Hz}$ and $<0.4 \mathrm{~Hz}$, considered as parasympathetic component, and the LF:HF ratio, considered to be an estimation of the relative sympathetic and parasympathetic balance, as well as a triangular index ${ }^{20}$. Elevated heart rate and HRV abnormalities were defined as $\geq 1$ abnormality in those seven categories based on $\leq 5$ or $\geq 95^{\text {th }}$ percentiles in age- and sex-matched control subjects measured using the same equipment.

Peripheral nerve function was measured by vibration threshold at the left malleolus and left great toe and thermal threshold function testing for hot and cold at the dorsum of the left foot (TSA; 2001 Neurosensory Analyzer Model TSA-II (Vibratory Sensory Analyzer; VSA-3000Option)). Normal ranges based on reference data from non-diabetic controls, adjusted for age and gender and measurements outside the $95^{\text {th }}$ percentile on $\geq 1$ of these four tests were considered abnormal.

This article is protected by copyright. All rights reserved. 
Diabetic retinopathy (DR) was determined from seven-field stereoscopic fundus photos (Topcon Fundus camera TRC 50-VT, Tokyo Optical Co., Tokyo) taken through (cyclopentolate 1\% and phenylephrine 2.5\%) dilated pupils and graded (modified Airlie House classification $^{21}$ ) by a single ophthalmologist. DR was defined as presence of at least one microaneurysm or hemorrhage (Early Treatment Diabetic Retinopathy Study (ETDRS Score) $\geq 21$ ). Retinopathy severity was based on the worse eye and categorized as none, minimal non-proliferative, mild to moderate non-proliferative, or proliferative DR.

Laboratory measures. Blood was centrifuged (3000 rpm, $10 \mathrm{~min}, 10^{\circ} \mathrm{C}$ ) and plasma stored $\left(-80^{\circ} \mathrm{C}\right)$ until analysis for CRP by high sensitivity assay (hsCRP) and sE-selectin at the National Health and Medical Research Centre (NHMRC) Clinical Trial Centre (University of Sydney). CRP was measured by high sensitivity turbidometry (Roche, Diagnostics, Basel, Switzerland on a Cobas Integra 400+) and a sE-selectin by ELISA (R\&D, Minneapolis, MN) with intra- and inter-assay coefficients of variation (CV) of less than $5 \%$ and $13 \%$, respectively.

Blood for HbA1c, WCC, ESR, lipids, liver, and renal function and urine for albuminuria was analyzed in the CHW clinical laboratories. HbA1c was evaluated by high-performance liquid chromatography (Adams Arkray Inc., Kyoto, Japan). Lipid profiles and serum creatinine were assessed by routine laboratory methods and urinary ACR was measured with an Immulite 1000 immunoassay analyzer (Siemens, Los Angeles, CA, USA). Abnormal values were defined by Australian clinical guidelines.

This article is protected by copyright. All rights reserved. 
Statistics. Data were analyzed using SPSS version 24 (Armonk, USA). Statistical significance was taken at $\mathrm{p}<0.05$. Normal distribution of variables was tested using the KolmogorovSmirnov test. Descriptive analyses calculated the mean \pm SD or median and interquartile range for continuous variables and the number and percentage for categorical variables. Differences between groups were analysed using ANOVA (with Bonferroni post-hoc test) for normally distributed variables and Kruskall-Wallis ANOVA (with Mann-Whitney test) for nonnormally distributed variables (with Bonferroni correction for multiple comparisons). For categorical variables chi-square test was used.

Univariate and multivariate logistic regression were used to analyze associations between complication status and laboratory results. Microvascular complications were defined as presence of either microalbuminuria, peripheral nerve abnormalities or diabetic retinopathy. Statistically significant and clinical important explanatory variables were included in multivariate analysis models. Covariates examined were HbA1c, diabetes duration and BMI which are routinely available and widely accepted to influence the clinical outcome of diabetes $^{22-25}$.

\section{Results}

\section{Clinical characteristics}

This article is protected by copyright. All rights reserved. 
Demographics of the 192 study participants with diabetes are shown in Table 1 . Mean age was 15.6 (SD 2.5) years and 49\% were female (diabetes patients vs. controls: 15.6 (SD 2.5) vs. 14.0 (SD 2.7) years, 51\% vs. 42\% girls). Adolescents with T1D were slightly older, had longer diabetes duration and higher HbA1c levels. Adolescents with T2D had higher BMI, more hypertension, and greater lipid abnormalities than those with T1D. Relative to the T1D group, adolescents with CFRD had lower BMI and cholesterol levels, higher triglyceride levels and more abnormal liver function tests.

\section{Inflammatory markers}

Inflammatory markers are shown in Figure 1. In healthy and CF subjects levels of hsCRP and sE-selectin (median (LQ-UQ)) were $0.4(0.2-0.8) \mathrm{mg} / \mathrm{L}$ and 38.9 (27.4-60.4) ng/ml and 1.0 (0.1-1.6) $\mathrm{mg} / \mathrm{L}$ and 58.0 (42.9-78.6) $\mathrm{ng} / \mathrm{ml}$ respectively. The hsCRP and sE-selectin levels were significantly higher in T2D and CFRD groups than in the reference group: 2.3 (1.0-4.5) $\mathrm{mg} / \mathrm{L}(\mathrm{p}<0.0001)$ and $62.6(46.4-80.7) \mathrm{ng} / \mathrm{ml}(\mathrm{p}=0.0005)$ and $1.6(0.5-5.0) \mathrm{mg} / \mathrm{L}(\mathrm{p}=0.003)$ and 71.5 (48.5-115.8) ng/mL ( $\mathrm{p}=0.0002)$ respectively. There was no difference between hsCRP and sE-selectin levels between T1D and healthy subjects $(0.5(0.3-1.4) \mathrm{mg} / \mathrm{L}$ $(\mathrm{p}=0.09)$ and 42.1 (33.1 - 55.0) ng/ml ( $\mathrm{p}=0.68)$ respectively).

Median WCC and ESR levels of T1D (6.3 (5.4-7.6) x10 $/ \mathrm{L}$ and $7.0(4.0-15.0) \mathrm{mm} / \mathrm{hr}$ respectively) and T2D (8.8 (7.2-10.2) x10\% $/ \mathrm{L}$ and $13.0(9.0-30.0) \mathrm{mm} / \mathrm{hr}$ respectively) were within the accepted reference range (WCC for $5-10$ years of age $5.0-14.5 \times 10^{9} / \mathrm{L}$, for $10-15$ years $4.5-13.5 \times 10^{9} / \mathrm{L}$, for $>15$ years $4.0-11.5 \times 10^{9} / \mathrm{L}$, ESR $0-20 \mathrm{~mm} / \mathrm{hr}$, except males $>15$ years $0-15 \mathrm{~mm} / \mathrm{hr}$ ). Levels of hsCRP and sE-selectin tended to be lower in the CF (non- 
diabetic) reference group compared to CFRD: $1.0(0.1-1.6)$ vs. $1.6(0.5-5.0) \mathrm{mg} / \mathrm{L}(\mathrm{p}=0.08)$, 58.0 (42.9-78.6) ng/ml vs. 71.5 (48.5-115.8) ng/ml ( $\mathrm{p}=0.17)$ respectively. As shown in Figure 1, relative to T1D subjects each inflammatory biomarker level was higher in T2D (hsCRP $\mathrm{p}<0.0001$, sE-selectin $\mathrm{p}<0.0001$, WCC $\mathrm{p}<0.0001$, ESR $\mathrm{p}=0.005$ ) and in CFRD (hsCRP $\mathrm{p}=0.001$, sE-selectin $\mathrm{p}<0.001$, WCC $\mathrm{p}=0.02$, ESR $\mathrm{p}=0.01$ ).

After adjusting for BMI, diabetes duration, and HbA1c the levels of inflammatory markers remain significantly higher in CFRD compared to T1D (Figure 2). We also observed significantly higher levels of biomarkers in CFRD compared to T2D (hsCRP p=0.002, sEselectin $\mathrm{p}=0.002$, ESR $\mathrm{p}=0.003$ ).

hsCRP and ESR were significantly higher in subjects with diabetes complications vs. those without: 0.9 (0.3-2.7) mg/L vs. 0.5 (0.3-1.4) mg/L (p=0.02) and 10.0 (5.0-22.0) mm/hr vs. 7.0 (3.5-14.0) $\mathrm{mm} / \mathrm{hr}(\mathrm{p}=0.04)$ respectively.

Six participants (2 with T1D, 1 with T2D, 2 with CFRD and 1 healthy control) had hsCRP levels $>10 \mathrm{mg} / \mathrm{L}$. The frequency of higher CRP levels was not significantly different between groups and therefore these subjects were included in the analysis. The exclusion of those did not significantly change the results (supplementary material).

\section{Complications status}

T2D participants had the most chronic complications, followed by T1D and then CFRD patients, independently of diabetes duration. Albuminuria was most common in T2D (19\% vs. $1 \%$ vs $0 \%)$. The T1D group had less autonomic nerve abnormalities than the T2D or CFRD 
groups (28\% vs. $54 \%$ vs. $50 \%$ ) and less peripheral nerve abnormalities than T2D (5\% vs. 19\%). Retinopathy was most common in T1D (16\% vs. (T2D) 7\% vs. (CFRD) 8\%), but these differences did not reach statistical significance.

\section{Relationships between diabetes complications and clinical characteristics including body habitus and inflammation}

HbA1c, BMI, BP, and inflammatory markers were significantly associated with individual complication types (Table 2). The ESR level was associated independently with overall complication status, in addition to age, gender, HbA1c, BMI, and BP. In individual complication analyses hsCRP, WCC, and ESR were associated with HRV abnormalities. The ESR level was associated with complications in the group with retinopathy, peripheral nerve abnormalities, and albuminuria.

The rates of BMI categories in T1D, T2D, and CFRD are shown in Table 3. As expected, T2D was associated with the highest rate of obesity and CRFD was associated with the highest rates of being underweight. Of T1D youth, $40 \%$ were overweight or obese. Inflammation and diabetes complication status were explored in relation to BMI category (underweight, normal weight, overweight, obesity). Inflammatory markers differed by body habitus; in particular obese patients had higher levels of most inflammatory biomarkers relative to all other weight categories. Only the WCC was significantly higher in underweight patients. Also, overall in the diabetes groups a pattern of complications being more common with increasing BMI was noted. As there were relatively few underweight subjects they were 
also grouped with normal weight subjects, and the differences in hsCRP levels and prevalence of diabetes complications remained statistically significant. 


\section{Discussion}

In this cross-sectional study of adolescents with T1D, T2D, and CFRD we found significant differences in levels of inflammatory biomarkers by diabetes type and by chronic complication status. Generally, inflammation levels were comparable in CRFD and T2D patients, with both being higher than in T1D. hsCRP and sE-selectin levels were numerically, but not statistically significantly, higher in all diabetes types relative to non-diabetic groups. Besides a high prevalence of chronic complications in T2D and CFRD we noted and explored strong associations between the presence of chronic complications and BMI and concurrent HbA1c levels. The observed link between the general complication status and BMI might be explained by or contributed to by higher levels of inflammatory markers and by increased complication prevalence in obese participants. To the best of our knowledge, this is the first study directly comparing inflammation biomarker levels in youth with T1D, T2D, and CFRD, the chronic diabetes complications and to assess the relationships of body weight with complications and inflammation levels.

Regarding chronic complications, while accepted, albeit early, evidence of retinal, renal, and neurologic complications was utilized, it was disconcerting to note their presence at a similar high prevalence (56-72\%) in all three groups of youth with diabetes. Retinopathy rates did not differ significantly between groups. Of particular concern, the known diabetes durations for the T2D and CFRD groups were quite short, at 1.8 and 2.3 years respectively, yet their chronic diabetes complication rates were as high as those with T1D, with a mean duration of 8.1 years. Unlike T1D, which presents acutely, it is possible that T2D and CFRD had been 
relatively asymptomatic and present for some years prior to their formal diagnosis. This emphasizes the importance of regular screening for diabetes in CF patients and in children and adolescents at risk for T2D. Recommended risk factors for screening for T2D in youth are obesity, a high-risk ethnic group, and a family history of T2D in the parents or grandparents ${ }^{26}$. We acknowledge a potential difference in our results may be caused by different diabetes duration between groups, but it is probable that with longer duration even more T2D and CFRD subjects may have developed chronic complications.

Neuropathy abnormalities, in particular HRV changes, were the most common type of diabetes complication in all three diabetes types. Yet, even though screening can be performed with a readily available EKG instrument, this test is not usually used in clinical practice. While retinopathy and peripheral nerve abnormalities rates were similar in all diabetes types, significantly higher rates of renal and neuropathic (microalbuminuria and HRV) abnormalities were found in T2D. Similar observations have been made previously ${ }^{4}$, though usually in older patients with and longer diabetes duration ${ }^{5,27}$. A study of complication prevalence in T1D and T2D patients of comparable age and diabetes duration to those in our study found higher rates of microalbuminuria, but similar rates of retinopathy in T1D and T2D participants, in spite of shorter diabetes duration and lower HbA1c levels in those with T2D diabetes ${ }^{4}$. Likewise, retinopathy was infrequent in T2D and CFRD in our study group, even though a very sensitive detection method was used. Our participants with T1D with longer diabetes duration and higher HbA1c levels had higher rates of retinopathy, which is consistent with other earlier studies ${ }^{28-31}$. With respect to the prevalence of HRV changes and 
retinopathy in CFRD, we identified higher prevalence rates than in earlier studies ${ }^{32,33}$, and given their short known diabetes duration, this should raise awareness of the danger of underestimating the risk of long-term complications in CFRD. Although the incidences of certain complications were high in this study, the absolute numbers respectively were low in this young age group. Given the recognized associations between one microvascular diabetes complication and other microvascular complications, and between micro and macrovascular end-points, we used a composite endpoint for microvascular complications ${ }^{34,35}$.

Overall, relatively little is known about the long-term complication rates in CFRD, and to date few studies have investigated the prevalence of diabetes complications in CFRD with short disease duration. This is likely because the life expectancy of CF was previously much shorter than it is now, and CFRD patients often did not survive long enough to develop chronic diabetes complications. Given their increasingly long mean survival rate, now to 45 years ${ }^{36}$, attention to their diabetes and diabetes complication status and risk factor control is increasingly important. The relationship between abnormalities in glucose metabolism and mutation of the cystic fibrosis transmembrane conductance regulator (CFTR) protein is not yet fully understood and the factors promoting chronic complications in CFRD are even less certain. We suggest that inflammation is one of these promoters. It is well-accepted that in $\mathrm{CF}$, pancreatic biliary duct obstruction results in both exocrine and endocrine pancreatic dysfunction $^{37}$, and there is also respiratory tract obstruction with epithelial destruction and proliferation of bacteria ${ }^{38}$. Hence, CF in general is characterized by chronic systemic and lung inflammation, even in the absence of pathogens ${ }^{39,}{ }^{40}$. With diabetes as a co-morbidity of CF, 
affecting $50 \%$ by the age of 30 years ${ }^{41}$, another state of vascular inflammation is added to this complex disease. In our study, we demonstrate similar levels of systemic inflammatory markers in CFRD as in T2D, which may provide an alarming signal that the risk for long-term complications in CFRD is also elevated compared to in T1D, and therefore underestimated and undertreated ${ }^{32}$. Future investigations, including more general and vascular-specific inflammation markers (e.g., sVCAM-1, sICAM-1 and interleukin-8 ${ }^{8,42}$ ), could increase our insight into inflammation in CFRD. Nevertheless, sE-selectin levels, which arise from arterial endothelial cells and reflect vascular inflammation, were highest in the CFRD group, being significantly higher than in the T1D group. We demonstrated similarly elevated sE-selectin levels in both the non-diabetic and diabetic CF patients, suggesting that endothelial dysfunction can occur in CF even in the absence of diabetes. CRP has many vascular and nonvascular tissues of origin, and the American Heart Association guideline on the assessment of cardiovascular risk ${ }^{43}$ recommends that levels $<1,1-2,2-3$ and $>3 \mathrm{mg} / \mathrm{L}$ represent normal, low, medium, high and very high CVD risk. Levels over $10 \mathrm{mg} / \mathrm{L}$ are often taken to reflect acute infection $^{12}$. Even in our young T2D study group hsCRP levels were high, consistent with moderate CVD risk. hsCRP levels in CFRD were not far below those in T2D, and were even higher when adjusted for covariates reflecting very high CVD risk, hence the inflammation-related CVD risk in CFRD should not be underrated ${ }^{44}$. Although levels of all inflammatory markers were numerically lower in the healthy reference group compared to all the other study groups, the results were not statistically significant, which may relate to study size.

This article is protected by copyright. All rights reserved. 
Concerning clinically available biomarkers for early chronic diabetes complications, our study found higher ESR levels were significantly associated with higher rates of complications. In particular, HRV abnormalities were associated with higher ESR, WCC and hsCRP levels. While associations have previously been reported for hsCRP ${ }^{45,46}$, associations for WCC and ESR have not previously been reported.

Our findings of higher systemic and vascular inflammation markers in youth with T2D and CRFD with versus without complications, and a trend toward higher levels than in reference groups support an association between inflammation and the pathogenesis of chronic diabetes complications, as has been proposed for retinopathy ${ }^{47}$, nephropathy ${ }^{48}$ and atherosclerosis, and as our results also suggest, for autonomic neuropathy. With further exploration, these inflammatory markers may be useful prognostic markers at the individual level for complication screening and monitoring, perhaps as part of risk equations. Our results also support the potential of anti-inflammatory drugs being used to prevent or treat diabetes complications. The use of anti-inflammatory drugs such as salsalate in diabetes has not only reduced the levels of markers of inflammation but also improved glucose metabolism ${ }^{49}$. Statins and ACE inhibitors, which are used to prevent vascular damage, can also reduce inflammatory markers ${ }^{50,51}$.

Reflecting the general population, many of the youth with diabetes in our study were overweight or obese, with only 54\% being of normal weight. A normal BMI was most prevalent in the CFRD group, and 16\% of the CFRD were underweight. In spite of the youth 
of our study subjects, we found that an elevated BMI was associated with higher inflammatory marker levels and chronic diabetes complications. Others have observed these phenomena $^{22,52}$, especially obesity, peripheral nerve abnormalities, and microalbuminuria in older patients with T1D and T2D ${ }^{53,54}$. Elevated hsCRP levels have previously been reported in young obese T2D patients compared to obese non-diabetic controls ${ }^{52}$. Consequently, reducing central adiposity should be a therapeutic target not only in young T2D patients, but also in T1D and (if relevant) CFRD patients.

In contrast to the other inflammatory markers, WCC showed an inverse relationship with BMI, being significantly higher in underweight patients. As most underweight subjects were in the CFRD group, this may reflect current and recurrent infections, which may also contribute to their low body weight. Other studies with healthy adolescents not including CFRD patients have demonstrated the expected positive correlation between WCC and $\mathrm{BMI}^{55,56}$.

Females have been shown to have higher complication rates in youth with $\mathrm{T}^{\mathrm{D}} \mathrm{D}^{57-59}$. In our statistical analyses, gender was not associated with any significant differences in complication status or in inflammatory marker levels. Previous studies have shown generally higher levels of inflammation in females, related to higher levels of body fat ${ }^{60-62}$.

Study strengths were the assessment of three types of diabetes in youth, which have never been compared in this way before. Furthermore, we evaluated childhood/adolescent groups with few co-morbidities, limited smoking history or use of anti-inflammatory medications, 
and had access to a detailed clinical characterization of each participant, in particular of their complication status. Recent severe hypoglycaemia was a criteria for study exclusion, and we also expect that hypoglycaemia would have been most likely in insulin treated subjects, hence in the T1D group, which tended to have lower inflammation levels than our T2D and CRFD groups.

Additionally, multiple inflammation markers were measured, most of which are routinely available in clinical laboratories, which enhances the potential for study replication and transfer into clinical practice. Our study was limited by its cross-sectional nature with measures of inflammation at a single time-point, the absence of non-diabetic groups with all biomarkers assessed and the lack of diabetic subject numbers to allow analyses related to specific individual complications. Other measures, such as of vascular function (sVCAM-1, sICAM and vascular reactivity), and other novel vascular risk markers (e.g. oxidative stress, microRNAs) are of interest. Larger groups would provide greater statistical power.

In conclusion, in a cross-sectional study of children and adolescents with T1D, T2D, or CFRD, and non-diabetic reference groups, elevated markers of systemic and vascular inflammation were evident, and similar in T2D and CFRD. High rates of early chronic complications were present and related to BMI, HbA1c and BP. Elevated BMI was common, and was associated with elevated inflammatory biomarkers and complication status. Early screening for T2D and CRFD in at-risk groups and for complications in all youth related diabetes is merited. Inflammation may be both a cause and effect of diabetes and its complications, and is a potential therapeutic target. Larger and longitudinal studies and intervention studies of anti-inflammatory agents are of interest. 


\section{Acknowledgments}

The authors thank study participants and the clinical and administration staff at CHW. AJJ is supported by a NHMRC Practitioner Fellowship and is a Sydney Medical School Foundation Fellow.

Funding: Regional Diabetes Support Scheme Grant, Novo Nordisk 2011

This article is protected by copyright. All rights reserved. 


\section{References}

1. Shoelson SE, Lee J, Goldfine AB. Inflammation and insulin resistance. The Journal of clinical investigation. 2006; 116:1793-801.

2. Goldberg RB. Cytokine and cytokine-like inflammation markers, endothelial dysfunction, and imbalanced coagulation in development of diabetes and its complications. The Journal of clinical endocrinology and metabolism. 2009; 94:3171-82.

3. Domingueti CP, Dusse LM, Carvalho M, de Sousa LP, Gomes KB, Fernandes AP. Diabetes mellitus: The linkage between oxidative stress, inflammation, hypercoagulability and vascular complications. Journal of diabetes and its complications. 2016; 30:738-45.

4. Eppens MC, Craig ME, Cusumano J, Hing S, Chan AK, Howard NJ, et al. Prevalence of diabetes complications in adolescents with type 2 compared with type 1 diabetes. Diabetes Care. 2006; 29:1300-6.

5. Song SH. Complication characteristics between young-onset type 2 versus type 1 diabetes in a UK population. BMJ open diabetes research \& care. 2015; 3:e000044.

6. Sibley SD, Thomas W, de Boer I, Brunzell JD, Steffes MW. Gender and elevated albumin excretion in the Diabetes Control and Complications Trial/Epidemiology of Diabetes Interventions and Complications (DCCT/EDIC) cohort: role of central obesity. American journal of kidney diseases : the official journal of the National Kidney Foundation. 2006; 47:223-32.

This article is protected by copyright. All rights reserved. 
7. Price SA, Gorelik A, Fourlanos S, Colman PG, Wentworth JM. Obesity is associated with retinopathy and macrovascular disease in type 1 diabetes. Obesity research \& clinical practice. 2014; 8:e178-82.

8. Chmiel JF, Berger M, Konstan MW. The role of inflammation in the pathophysiology of CF lung disease. Clinical reviews in allergy \& immunology. 2002; 23:5-27.

9. Chmiel JF, Davis PB. State of the art: why do the lungs of patients with cystic fibrosis become infected and why can't they clear the infection? Respiratory research. 2003; 4:8.

10. Pepys MB, Hirschfield GM. C-reactive protein: a critical update. The Journal of clinical investigation. 2003; 111:1805-12.

11. Choi J, Joseph L, Pilote L. Obesity and C-reactive protein in various populations: a systematic review and meta-analysis. Obesity reviews : an official journal of the International Association for the Study of Obesity. 2013; 14:232-44.

12. Huizen J. What does it mean if you have a high C-reactive protein? MedicalNewsToday2018.

13. Berliner JA, Navab M, Fogelman AM, Frank JS, Demer LL, Edwards PA, et al. Atherosclerosis: basic mechanisms. Oxidation, inflammation, and genetics. Circulation. 1995; 91:2488-96.

14. Lopes-Virella MF, Baker NL, Hunt KJ, Cleary PA, Klein R, Virella G. Baseline markers of inflammation are associated with progression to macroalbuminuria in type 1 diabetic subjects. Diabetes Care. 2013; 36:2317-23.

This article is protected by copyright. All rights reserved. 
15. Rajab HA, Baker NL, Hunt KJ, Klein R, Cleary PA, Lachin J, et al. The predictive role of markers of Inflammation and endothelial dysfunction on the course of diabetic retinopathy in type 1 diabetes. Journal of diabetes and its complications. 2015; 29:108-14.

16. Pan H, Cole TJ. User’s guide to lmschartmaker. UK Medical Research Council. 2005.

17. WHO, Multicentre, Growth, Reference, Study, Group. WHO Child Growth Standards: Length/height-for-age, weight-for-age, weight-for-length, weight-for-height and body mass index-for-age: Methods and development. Geneva: World Health Organization. 2006:312.

18. Report of the Second Task Force on Blood Pressure Control in Children--1987. Task Force on Blood Pressure Control in Children. National Heart, Lung, and Blood Institute, Bethesda, Maryland. Pediatrics. 1987; 79:1-25.

19. Cho YH, Craig ME, Jopling T, Chan A, Donaghue KC. Higher body mass index predicts cardiac autonomic dysfunction: A longitudinal study in adolescent type 1 diabetes. Pediatric diabetes. 2018.

20. Heart rate variability: standards of measurement, physiological interpretation and clinical use. Task Force of the European Society of Cardiology and the North American Society of Pacing and Electrophysiology. Circulation. 1996; 93:1043-65.

21. Klein R, Klein BE, Moss SE, Davis MD, DeMets DL. The Wisconsin epidemiologic study of diabetic retinopathy. IV. Diabetic macular edema. Ophthalmology. 1984; 91:1464-74.

22. Gray N, Picone G, Sloan F, Yashkin A. Relation between BMI and diabetes mellitus and its complications among US older adults. Southern medical journal. 2015; 108:29-36.

This article is protected by copyright. All rights reserved. 
23. Shamshirgaran SM, Mamaghanian A, Aliasgarzadeh A, Aiminisani N, IranparvarAlamdari M, Ataie J. Age differences in diabetes-related complications and glycemic control. BMC endocrine disorders. 2017; 17:25.

24. Maric-Bilkan C. Sex differences in micro- and macro-vascular complications of diabetes mellitus. Clinical science (London, England : 1979). 2017; 131:833-46.

25. Dost A, Bechtold-Dalla Pozza S, Bollow E, Kovacic R, Vogel P, Feldhahn L, et al. Blood pressure regulation determined by ambulatory blood pressure profiles in children and adolescents with type 1 diabetes mellitus: Impact on diabetic complications. Pediatric diabetes. 2017; 18:874-82.

26. Shaw J. Epidemiology of childhood type 2 diabetes and obesity. Pediatric diabetes. 2007; 8 Suppl 9:7-15.

27. Constantino MI, Molyneaux L, Limacher-Gisler F, Al-Saeed A, Luo C, Wu T, et al. Long-term complications and mortality in young-onset diabetes: type 2 diabetes is more hazardous and lethal than type 1 diabetes. Diabetes Care. 2013; 36:3863-9.

28. Mayer-Davis EJ, Davis C, Saadine J, D'Agostino RB, Jr., Dabelea D, Dolan L, et al. Diabetic retinopathy in the SEARCH for Diabetes in Youth Cohort: a pilot study. Diabetic medicine : a journal of the British Diabetic Association. 2012; 29:1148-52.

29. Maguire A, Chan A, Cusumano J, Hing S, Craig M, Silink M, et al. The case for biennial retinopathy screening in children and adolescents. Diabetes Care. 2005; 28:509-13.

30. Yung B, Landers A, Mathalone B, Gyi KM, Hodson ME. Diabetic retinopathy in adult patients with cystic fibrosis-related diabetes. Respiratory medicine. 1998; 92:871-2. 
31. Farah SE, Wals KT, Friedman IB, Pisacano MA, DiMartino-Nardi J. Prevalence of retinopathy and microalbuminuria in pediatric type 2 diabetes mellitus. Journal of pediatric endocrinology \& metabolism : JPEM. 2006; 19:937-42.

32. Schwarzenberg SJ, Thomas W, Olsen TW, Grover T, Walk D, Milla C, et al. Microvascular complications in cystic fibrosis-related diabetes. Diabetes Care. 2007; 30:1056-61.

33. van den Berg JM, Morton AM, Kok SW, Pijl H, Conway SP, Heijerman HG. Microvascular complications in patients with cystic fibrosis-related diabetes (CFRD). Journal of cystic fibrosis : official journal of the European Cystic Fibrosis Society. 2008; 7:515-9.

34. Grunwald JE, Pistilli M, Ying GS, Maguire M, Daniel E, Whittock-Martin R, et al. Retinopathy and the risk of cardiovascular disease in patients with chronic kidney disease (from the Chronic Renal Insufficiency Cohort study). The American journal of cardiology. 2015; 116:1527-33.

35. Karlberg C, Falk C, Green A, Sjolie AK, Grauslund J. Proliferative retinopathy predicts nephropathy: a 25-year follow-up study of type 1 diabetic patients. Acta diabetologica. 2012; 49:263-8.

36. Foundation CF. Cystic Fibrosis Foundation Patient Registry, 2015 Annual Data Report. 2015 Annual Data Report. Cystic Fibrosis Foundation, Bethesda, Maryland, 2016.

37. Lohr M, Goertchen P, Nizze H, Gould NS, Gould VE, Oberholzer M, et al. Cystic fibrosis associated islet changes may provide a basis for diabetes. An 
immunocytochemical and morphometrical study. Virchows Archiv A, Pathological anatomy and histopathology. 1989; 414:179-85.

38. Rottner M, Tual-Chalot S, Mostefai HA, Andriantsitohaina R, Freyssinet JM, Martinez MC. Increased oxidative stress induces apoptosis in human cystic fibrosis cells. PloS one. 2011; 6:e24880.

39. Conese M, Copreni E, Di Gioia S, De Rinaldis P, Fumarulo R. Neutrophil recruitment and airway epithelial cell involvement in chronic cystic fibrosis lung disease. Journal of cystic fibrosis : official journal of the European Cystic Fibrosis Society. 2003; 2:129-35.

40. Courtney JM, Dunbar KE, McDowell A, Moore JE, Warke TJ, Stevenson M, et al. Clinical outcome of Burkholderia cepacia complex infection in cystic fibrosis adults. Journal of cystic fibrosis : official journal of the European Cystic Fibrosis Society. 2004; 3:93-8.

41. Andersen HU, Lanng S, Pressler T, Laugesen CS, Mathiesen ER. Cystic fibrosis-related diabetes: the presence of microvascular diabetes complications. Diabetes Care. 2006; 29:2660-3

42. Bergin DA, Hurley K, Mehta A, Cox S, Ryan D, O'Neill SJ, et al. Airway inflammatory markers in individuals with cystic fibrosis and non-cystic fibrosis bronchiectasis. Journal of inflammation research. 2013; 6:1-11.

43. Goff DC, Jr., Lloyd-Jones DM, Bennett G, Coady S, D'Agostino RB, Sr., Gibbons R, et al. 2013 ACC/AHA guideline on the assessment of cardiovascular risk: a report of the American College of Cardiology/American Heart Association Task Force on Practice Guidelines. Journal of the American College of Cardiology. 2014; 63:2935-59.

This article is protected by copyright. All rights reserved. 
44. O'Shea D, O'Connell J. Cystic fibrosis related diabetes. Current diabetes reports. 2014; $14: 511$.

45. Anan F, Takahashi N, Nakagawa M, Ooie T, Saikawa T, Yoshimatsu H. High-sensitivity C-reactive protein is associated with insulin resistance and cardiovascular autonomic dysfunction in type 2 diabetic patients. Metabolism: clinical and experimental. 2005; 54:552-8.

46. Muni RH, Kohly RP, Lee EQ, Manson JE, Semba RD, Schaumberg DA. Prospective study of inflammatory biomarkers and risk of diabetic retinopathy in the diabetes control and complications trial. JAMA ophthalmology. 2013; 131:514-21.

47. Antonetti DA, Barber AJ, Bronson SK, Freeman WM, Gardner TW, Jefferson LS, et al. Diabetic retinopathy: seeing beyond glucose-induced microvascular disease. Diabetes. 2006; 55:2401-11.

48. Wada J, Makino H. Inflammation and the pathogenesis of diabetic nephropathy. Clinical science (London, England : 1979). 2013; 124:139-52.

49. Fleischman A, Shoelson SE, Bernier R, Goldfine AB. Salsalate improves glycemia and inflammatory parameters in obese young adults. Diabetes Care. 2008; 31:289-94.

50. Jialal I, Miguelino E, Griffen SC, Devaraj S. Concomitant reduction of low-density lipoprotein-cholesterol and biomarkers of inflammation with low-dose simvastatin therapy in patients with type 1 diabetes. The Journal of clinical endocrinology and metabolism. 2007; 92:3136-40.

This article is protected by copyright. All rights reserved. 
51. Fliser D, Buchholz K, Haller H. Antiinflammatory effects of angiotensin II subtype 1 receptor blockade in hypertensive patients with microinflammation. Circulation. 2004; 110:1103-7.

52. Reinehr T, Karges B, Meissner T, Wiegand S, Stoffel-Wagner B, Holl RW, et al. Inflammatory Markers in Obese Adolescents with Type 2 Diabetes and Their Relationship to Hepatokines and Adipokines. The Journal of pediatrics. 2016; 173:131-5.

53. Smith AG, Singleton JR. Obesity and hyperlipidemia are risk factors for early diabetic neuropathy. Journal of diabetes and its complications. 2013; 27:436-42.

54. de Boer IH, Sibley SD, Kestenbaum B, Sampson JN, Young B, Cleary PA, et al. Central obesity, incident microalbuminuria, and change in creatinine clearance in the epidemiology of diabetes interventions and complications study. Journal of the American Society of Nephrology : JASN. 2007; 18:235-43.

55. Oliveira TM, de Faria FR, de Faria ER, Pereira PF, Franceschini SC, Priore SE. [Nutritional status, metabolic changes and white blood cells in adolescents]. Revista paulista de pediatria : orgao oficial da Sociedade de Pediatria de Sao Paulo. 2014; 32:351-9.

56. Perez-de-Heredia F, Gomez-Martinez S, Diaz LE, Veses AM, Nova E, Warnberg J, et al. Influence of sex, age, pubertal maturation and body mass index on circulating white blood cell counts in healthy European adolescents-the HELENA study. European journal of pediatrics. 2015; 174:999-1014.

57. Monti MC, Lonsdale JT, Montomoli C, Montross R, Schlag E, Greenberg DA. Familial risk factors for microvascular complications and differential male-female risk in a large 
cohort of American families with type 1 diabetes. The Journal of clinical endocrinology and metabolism. 2007; 92:4650-5.

58. Cho YH, Craig ME, Donaghue KC. Puberty as an accelerator for diabetes complications. Pediatric diabetes. 2014; 15:18-26.

59. Zoffmann V, Vistisen D, Due-Christensen M. A cross-sectional study of glycaemic control, complications and psychosocial functioning among 18- to 35-year-old adults with type 1 diabetes. Diabetic medicine : a journal of the British Diabetic Association. 2014; 31:493-9.

60. Cartier A, Cote M, Lemieux I, Perusse L, Tremblay A, Bouchard C, et al. Sex differences in inflammatory markers: what is the contribution of visceral adiposity? The American journal of clinical nutrition. 2009; 89:1307-14.

61. Thorand B, Baumert J, Doring A, Herder C, Kolb H, Rathmann W, et al. Sex differences in the relation of body composition to markers of inflammation. Atherosclerosis. 2006; $184: 216-24$.

62. Connelly PW, Hanley AJ, Harris SB, Hegele RA, Zinman B. Relation of waist circumference and glycemic status to C-reactive protein in the Sandy Lake Oji-Cree. International journal of obesity and related metabolic disorders : journal of the International Association for the Study of Obesity. 2003; 27:347-54.

This article is protected by copyright. All rights reserved. 


\section{Table and figure legends}

Table 1. Clinical characteristics for subjects according to diabetes type.

Table 2. Variables associated with diabetes complications.

Table 3. Median of inflammation makers with interquartile range and prevalence of diabetes complications by weight categories.

This article is protected by copyright. All rights reserved. 
Figure 1. Unadjusted blood levels of inflammation markers by diabetes type.

Figure 2. Adjusted blood levels of inflammation markers for diabetes duration, BMI and HbA1c by diabetes type. 
Table 1.

\begin{tabular}{|l|c|c|c|}
\hline & $\begin{array}{c}\text { T1D } \\
(\mathrm{n}=134)\end{array}$ & $\begin{array}{c}\text { T2D } \\
(\mathrm{n}=32)\end{array}$ & $\begin{array}{c}\text { CFRD } \\
(\mathrm{n}=32)\end{array}$ \\
\hline Age (years) & $15.8[2.6]$ & $15.1[1.9]$ & $14.6[2.2]^{2}$ \\
\hline Diabetes duration (years) & $8.1[5.4-10.5]^{1}$ & $1.8[0.3-3.3]$ & $2.3[1.0-3.9]^{2}$ \\
\hline BMI & $22.7[20.7-25.9]^{1}$ & $31.7[27.5-35.2]^{3}$ & $18.5[16.7-20.6]^{2}$ \\
\hline $\begin{array}{l}\text { Weight category: } \\
\text { Underweight/normal/overweight/obese } \\
\text { (\%) }\end{array}$ & $2 / 57 / 30 / 11$ & $0 / 3 / 22 / 75$ & $19 / 78 / 3 / 0$ \\
\hline HbA ${ }_{1 \mathrm{c}}(\%)$ & $8.5[7.7-9.5]^{1}$ & $6.6[5.6-9.2]$ & $5.9[5.7-6.5]^{2}$ \\
\hline Hypertension & $12 / 134[9 \%]$ & $6 / 31[19 \%]^{3}$ & $0 / 28[0 \%]$ \\
\hline Any complications & $87 / 134[65 \%]$ & $23 / 31[72 \%]$ & $18 / 28[56 \%]$ \\
\hline Microalbuminuria & $1 / 123[1 \%]^{1}$ & $6 / 20[19 \%]^{3}$ & $0 / 19[0 \%]$ \\
\hline HRV abnormalities & $35 / 126[28 \%]^{1}$ & $14 / 26[54 \%]$ & $12 / 24[50 \%]^{2}$ \\
\hline Elevated heart rate & $12 / 126[10 \%]^{1}$ & $9 / 26[35 \%]$ & $6 / 24[25 \%]^{2}$ \\
\hline Peripheral nerve abnormalities & $6 / 132[5 \%]$ & $6 / 31[19 \%]$ & $0 / 27[0 \%]$ \\
\hline Retinopathy & $21 / 133[16 \%]$ & $2 / 30[7 \%]$ & $2 / 26[8 \%]$ \\
\hline Elevated liver enzymes & $14 / 96[15 \%]$ & $7 / 26[27 \%]$ & $9 / 19[47 \%]^{2}$ \\
\hline \multicolumn{3}{|c|}{} & \multicolumn{2}{|c|}{} \\
\hline Abnormal lipid profile & $19 / 134[14 \%]^{1}$ & $15 / 31[48 \%]$ & $7 / 29[24 \%]$ \\
\hline Total cholesterol (mmol/L) & $4.4[3.8-4.9]$ & $4.7[4.1-5.2]^{3}$ & $3.2[2.8-3.7]^{2}$ \\
\hline Triglycerides (mmol/L) & $1.0[0.7-1.4]^{1}$ & $1.6[1.2-2.4]$ & $1.4[1.1-1.8]^{2}$ \\
\hline HDL-C (mmol/L) & $1.4[1.1-1.6]^{1}$ & $1.1[0.8-1.3]$ & $1.0[0.8-1.3]^{2}$ \\
\hline LDL-C (mmol/L) & $2.5[2.0-2.9]$ & $2.7[2.1-3.4]^{3}$ & $1.6[1.3-2.0]^{2}$ \\
\hline
\end{tabular}

${ }^{1}$ T1D vs. T2D ${ }^{2}$ T1D vs. CFRD ${ }^{3}$ T2D vs. CFRD; statistics reported like $\mathrm{X}[\mathrm{X}-\mathrm{X}]$ are medians [25 $5^{\text {th }}$ percentile- $75^{\text {th }}$ percentile], like $\mathrm{X}[\mathrm{X}]$ are means[SD], all values marked with an asterisk have significant p-values between the indicated diabetes groups in Bonferroni post-hoc test, Mann-Whitney test or 2x2 chi-square test. 
Table 2.

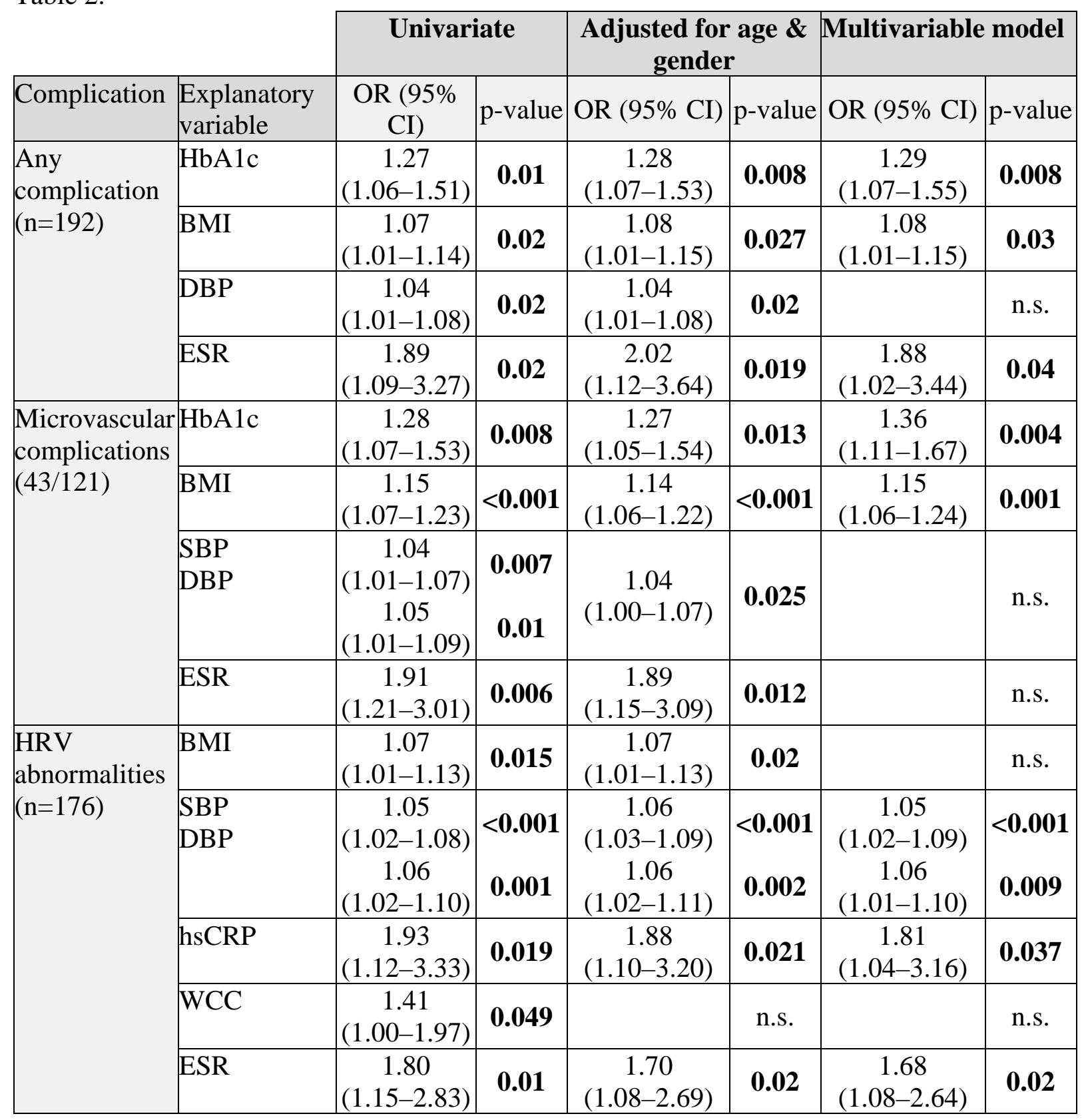

Multivariable model: explanatory variable adjusted for age, gender + BMI, SBP/DBP and HbA1c (if not yet explanatory variable).

For ESR, CRP, WCC and sE-selectin z-scores were used for logistic regression. 
Table 3.

\begin{tabular}{|c|c|c|c|c|c|}
\hline Outcome & $\begin{array}{c}\text { Underweight } \\
\left(<15^{\text {th }}\right. \\
\text { percentile })\end{array}$ & $\begin{array}{c}\text { Normal } \\
\left(\geq 15^{\text {th }} \& \leq 85^{\text {th }}\right. \\
\text { percentile })\end{array}$ & $\begin{array}{l}\text { Overweight } \\
\left(>85^{\text {th }} \&<97^{\text {th }}\right. \\
\text { percentile })\end{array}$ & $\begin{array}{c}\text { Obese } \\
\left(\geq 97^{\text {th }} \text { percentile) }\right.\end{array}$ & $\begin{array}{c}\mathrm{p}^{-} \\
\text {value* }\end{array}$ \\
\hline $\begin{array}{l}\% \text { of all diabetes } \\
\text { patients }\end{array}$ & 4 & 54 & 27 & 15 & \\
\hline T1D & 1 & 59 & 32 & 8 & \\
\hline T2D & 0 & 6 & 31 & 63 & $<0.001$ \\
\hline CFRD & 16 & 81 & 3 & 0 & \\
\hline $\begin{array}{l}\text { hsCRP } \\
\text { (mg/L) }\end{array}$ & $\begin{array}{c}0.12 \\
{[0.10-0.13]}\end{array}$ & $\begin{array}{c}0.44 \\
{[0.23-1.46]}\end{array}$ & $\begin{array}{c}1.04 \\
{[0.38-1.52]}\end{array}$ & $\begin{array}{c}2.94 \\
\left.[1.24-5.24]^{\prime}\right]\end{array}$ & 0.001 \\
\hline $\begin{array}{l}\text { sE-selectin } \\
\text { (ng/ml) }\end{array}$ & $\begin{array}{c}44.0 \\
{[35.0-52.9]} \\
\end{array}$ & $\begin{array}{c}47.6 \\
{[33.3-63.9]}\end{array}$ & $\begin{array}{c}43.4 \\
{[34.3-57.8]}\end{array}$ & $\begin{array}{c}51.5 \\
{[40.6-76.0]}\end{array}$ & 0.8 \\
\hline WCC $\left(\times 10^{9} / \mathrm{L}\right)$ & $\begin{array}{c}8.7 \\
{[6.5-14.0]} \\
\end{array}$ & $\begin{array}{c}6.6 \\
{[5.4-7.7]^{\llcorner}} \\
\end{array}$ & $\begin{array}{c}6.5 \\
{[5.7-8.1]^{\dagger}}\end{array}$ & $\begin{array}{c}7.9 \\
{[5.5-9.7]} \\
\end{array}$ & $<0.001$ \\
\hline ESR $(\mathrm{mm} / \mathrm{h})$ & $\begin{array}{c}5 \\
{[3-14]}\end{array}$ & $\begin{array}{c}8 \\
{[4-16.8]} \\
\end{array}$ & $\begin{array}{c}7 \\
{[3-15]}\end{array}$ & $\begin{array}{c}14.5 \\
{[8.3-29.8]} \\
\end{array}$ & 0.6 \\
\hline Any complication & $\begin{array}{c}4 / 7 \\
{[57 \%]}\end{array}$ & $\begin{array}{l}63 / 104 \\
{[61 \%]}\end{array}$ & $\begin{array}{l}37 / 52 \\
{[71 \%]}\end{array}$ & $\begin{array}{l}23 / 29 \\
{[79 \%]}\end{array}$ & 0.2 \\
\hline Microalbuminuria & $\begin{array}{c}0 / 5 \\
{[0 \%]}\end{array}$ & $\begin{array}{l}1 / 90 \\
{[1 \%]}\end{array}$ & $\begin{array}{l}3 / 46 \\
{[7 \%]} \\
\end{array}$ & $\begin{array}{c}3 / 20 \\
{[15 \%] ”}\end{array}$ & 0.04 \\
\hline \begin{tabular}{|l} 
HRV \\
abnormalities
\end{tabular} & $\begin{array}{c}3 / 7 \\
{[43 \%]}\end{array}$ & $\begin{array}{l}30 / 95 \\
{[32 \%]}\end{array}$ & $\begin{array}{l}13 / 47 \\
{[28 \%]}\end{array}$ & $\begin{array}{l}15 / 26 \\
{[58 \%]}\end{array}$ & 0.05 \\
\hline \begin{tabular}{|l|}
$\begin{array}{l}\text { Peripheral nerve } \\
\text { abnormalities }\end{array}$ \\
\end{tabular} & $\begin{array}{c}0 / 7 \\
{[0 \%]}\end{array}$ & $\begin{array}{l}3 / 103 \\
{[3 \%]} \\
\end{array}$ & $\begin{array}{l}1 / 50 \\
{[2 \%]}\end{array}$ & $\begin{array}{c}8 / 29 \\
[28 \%],] \\
\end{array}$ & $<0.001$ \\
\hline Retinopathy & $\begin{array}{c}0 / 6 \\
{[0 \%]}\end{array}$ & $\begin{array}{l}13 / 102 \\
{[13 \%]}\end{array}$ & $\begin{array}{l}10 / 51 \\
{[20 \%]}\end{array}$ & $\begin{array}{l}2 / 29 \\
{[7 \%]}\end{array}$ & 0.3 \\
\hline
\end{tabular}

*One way ANOVA or 4x2 chi-square test.

All individual p-values calculated with Bonferroni post-hoc test or 2x2 chi-square test.

$\dagger$ Underweight vs. Overweight: $\mathrm{p}=<0.05$; $\ddagger$ Underweight vs. Obese: $\mathrm{p}=<0.05$; ” Normal weight vs. Obese: $\mathrm{p}=<0.05 ;{ }^{\llcorner}$Underweight vs. Normal weight: $\mathrm{p}=<0.05 ;{ }^{j}$ Overweight vs. Obese: $\mathrm{p}=<0.05$ 

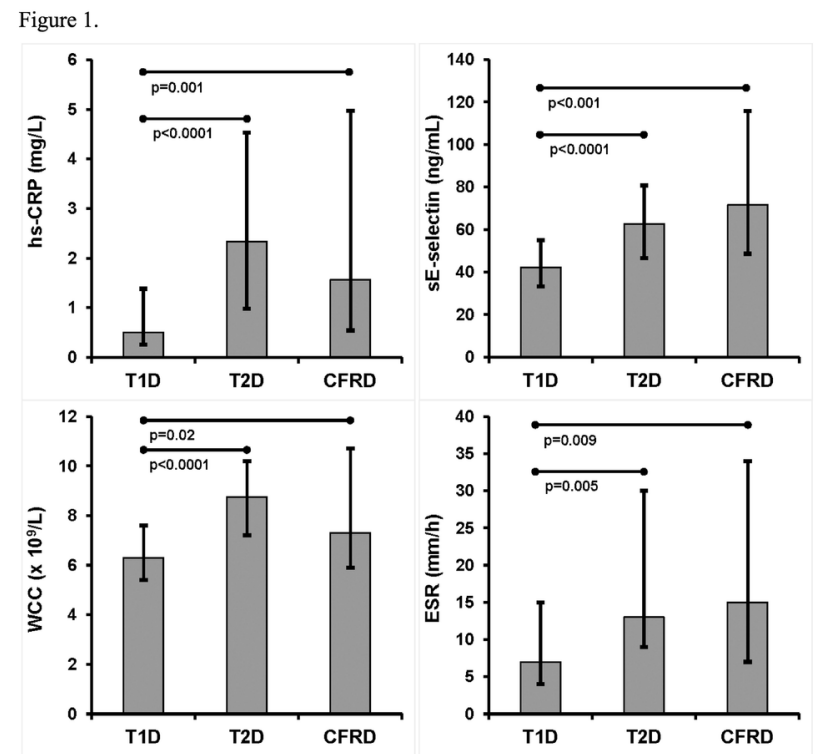

Medians and $25^{\text {th }}$ and $75^{\text {th }}$ percentile of biomarkers (unadjusted)

PEDI_12913_Figure1.tif 

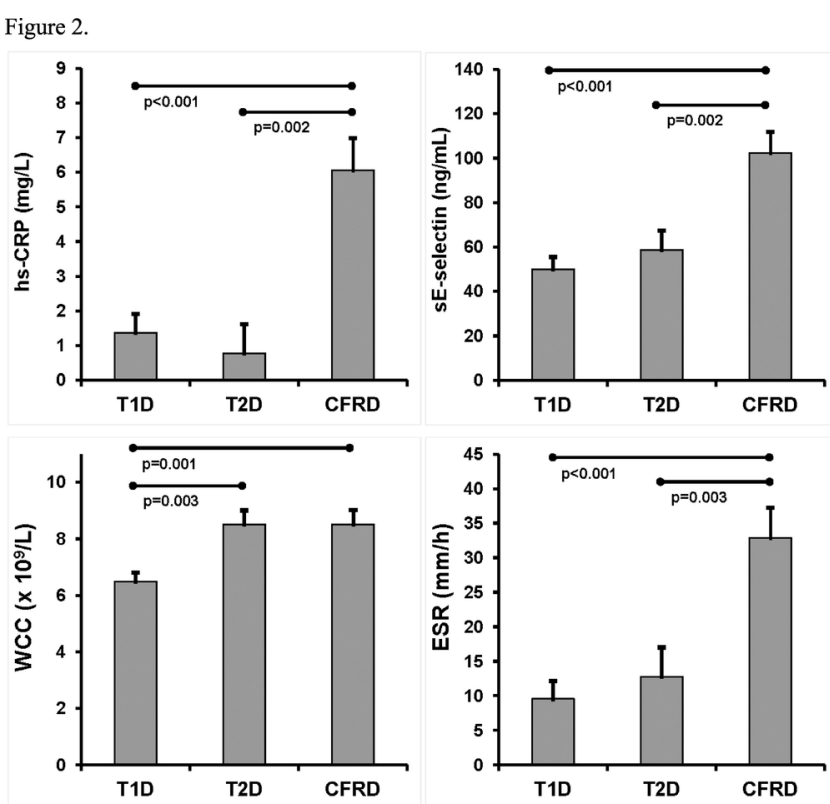

Means and SEM of biomarkers adjusted for diabetes duration, $\mathrm{HbA1c}$ level and BMI. PEDI_12913_Figure2.tif 


\section{University Library}

\section{- M M N E R VA A gateway to Melbourne's research publications}

Minerva Access is the Institutional Repository of The University of Melbourne

\section{Author/s:}

Aulich, J;Cho, YH;Januszewski, AS;Craig, ME;Selvadurai, H;Wiegand, S;Jenkins,

$\mathrm{AJ}$;Donaghue, $\mathrm{KC}$

Title:

Associations between circulating inflammatory markers, diabetes type and complications in youth

Date:

2019-12-01

Citation:

Aulich, J., Cho, Y. H., Januszewski, A. S., Craig, M. E., Selvadurai, H., Wiegand, S., Jenkins, A. J. \& Donaghue, K. C. (2019). Associations between circulating inflammatory markers, diabetes type and complications in youth. PEDIATRIC DIABETES, 20 (8), pp.1118-1127. https://doi.org/10.1111/pedi.12913.

Persistent Link:

http://hdl.handle.net/11343/286470 